\title{
GAMAESPECTROMETRIA APLICADA EM SOLO AGRÍCOLA NO NOROESTE DO ESTADO DO RIO DE JANEIRO
}

\author{
Andréa Cristina Lima dos Santos ${ }^{1}$, Paulo de Tarso Luiz Menezes² \\ e Carlos Tadeu Carvalho do Nascimento ${ }^{3}$ \\ Recebido em 15 fevereiro, 2008 / Aceito em 26 maio, 2008 \\ Received on February 15, 2008 / Accepted on May 26, 2008
}

\begin{abstract}
The present work presents the use of gamma-ray spectrometry applied to precision agriculture in a sub-tropical area. Our dataset comprises measurements both in rock and residual soil. The soil dataset shows a reduction of $20 \%$ on $\mathrm{U}$ and Th and $10 \%$ on $\mathrm{K}$, when compared to rock samples. This difference could be related to $\mathrm{K}$ supplementation associated to chemical fertilization.
\end{abstract}

Keywords: gamma-ray spectrometry, agriculture, soils, fertilizers.

RESUMO. 0 escopo deste trabalho consistiu no levantamento, processamento e interpretação dos dados de gamaespectrometria terrestre numa área utilizada para cultivo agrícola. Os dados observados indicam a perda de radioelementos dos solos em relação às rochas dos quais são oriundos. A comparação entre medidas em rocha e solos no levantamento terrestre aponta, para estes últimos, uma redução de cerca de 20\% dos elementos urânio e tório, e cerca de 10\% para o potássio. 0 menor percentual de perda para o potássio é associado, no presente trabalho, ao suprimento deste elemento no processo de fertilização química utilizada na área de estudo. Os resultados aqui obtidos apontam para uma adequação do uso deste método geofísico à identificação e ao monitoramento de áreas agrícolas no noroeste do Estado do Rio de Janeiro.

Palavras-chave: gamaespectrometria, agricultura, solos, fertilizantes.

\footnotetext{
${ }^{1}$ Instituto de Geociências, Universidade de Brasília, 70910-900 Brasília, DF, Brasil. Tel.: (61) 3307-2877; Fax: (61) 3340-4759 - E-mail: andrealima@unb.br ${ }^{2}$ Faculdade de Geologia, Universidade do Estado do Rio de Janeiro, Rua São Francisco Xavier, 524/2029 Bloco A, Maracanã, 20550-013 Rio de Janeiro, RJ, Brasil. Tel.: (21) 2587-7598; Fax: (21) 2254-6675 - E-mail: ptarsomenezes@pq.cnpq.br

${ }^{3}$ Instituto de Geociências, Universidade de Brasília, 70910-900 Brasília, DF, Brasil. Tel.: (61) 3429-6495; Fax: (61) 3340-4759 - E-mail: carlostadeu@unb.br
} 


\section{INTRODUÇ̃̃o}

A agricultura brasileira é um dos setores que mais vem contribuindo para 0 crescimento da economia do país. Em virtude disso, a busca de técnicas e ferramentas que contribuam para um aumento na produção dos diferentes cultivos tem sido um dos grandes objetivos da agricultura moderna. Em contrapartida, as más práticas agricultáveis resultam no mau funcionamento do solo e na degradação ambiental (Zalidis et al., 2002). Sendo assim, os processos de degradação dos solos agrícolas constituem um grave problema em nível mundial, com consequiências ambientais, econômicas e sociais significativas. Com o crescimento da agricultura brasileira, aumenta-se a necessidade de desenvolvimento de tecnologias que visem contribuir para a sua modernização, de forma a aumentar o contínuo crescimento da produtividade. Nisto consiste, pois, um grande desafio para a pesquisa: desenvolver tecnologias que atendam aos requerimentos sócio-econômicos, agronômicos e ecológicos de forma a equilibrar o desenvolvimento da cultura com a conservação do meio ambiente.

Os métodos geofísicos compreendem técnicas indiretas de investigação das estruturas em subsuperfície. Tais metodologias permitem estimar as condições geológicas através do contraste das propriedades físicas dos materiais de subsuperfície. No diagnóstico ambiental de áreas contaminadas e na investigação da estrutura de solos, a realização de levantamentos geofísicos tem por objetivo básico a identificação da presença da contaminação subterrânea além da definição das feições pedológicas e hidrogeológicas dos locais investigados. Neste âmbito, diversos trabalhos vêm sendo desenvolvidos envolvendo, principalmente, a aplicação de métodos elétricos e eletromagnéticos. Dentre eles pode-se destacar a aplicação do método resistivimétrico para o mapeamento da estrutura de solos (Tabbagh et al., 2000) e investigações sobre as condições hidrológicas (Pozdnyakova et al., 2001). 0 método GPR (Ground Penetrating Radar) também tem sido utilizado na definição de condições de intemperismo e geomorfologia de solos (Aranha et al., 2002). Metternicht \& Zinck (2003), utilizaram métodos eletromagnéticos para definir salinidade do solo causada por processos naturais ou humanos.

Inicialmente proposto para aplicação em prospecção mineral e mapeamento geológico (Vasconcellos et al., 1994), o método gamaespectrométrico ganhou espaço em aplicações referentes a estudos pedológicos e de meio ambiente (Dickson et al., 1996; Dickson \& Scott, 1997; Wilford et al., 1997; Thiessen et al., 1999). Nesta metodologia, mede-se a concentração do radioisótopo do potássio (K) e dos radioisótopos das séries do urânio
(U) e tório (Th) em rochas e solos. Estas concentrações são diretamente proporcionais à intensidade de radiação gama emitida pelo decaimento radioativo destes radioisótopos (Wilford et al., 1997). Também no Brasil, o método gamaespectrométrico vem sendo utilizado em monitoramentos ambientais e estudos de solos. Souza (1998) utilizou dados gamaespectrométricos para verificar relação em área agricultável com processos pedogenéticos e fertilização fosfatada. Seus estudos indicam que os elementos U e Th tendem a concentrar-se em solos oriundos do intemperismo de rochas básicas, mais desenvolvidos e argilosos. Bacchi et al. (1998) utilizaram a técnica de atenuação da radiação gama para determinar umidade e densidade de solo. Vaz et al. (1999) utilizaram essa mesma técnica para determinação de tamanho de partículas de solo. Estudando processos supergênicos atuantes sobre rochas graníticas, Rebelo (2000) observou que 0 elemento Th permanece fixo no solo, durante intemperismo e pedogênese. Nascimento et al. (2004) concluíram que solos do cerrado com textura argilosa e enriquecidos com matéria orgânica são mais radioativos que solos arenosos. Elias (2004) desenvolveu estudo teórico mostrando a vantagem de utilizar-se a radiação gama para análise granulométrica e determinação de coeficiente de atenuação da radiação no solo. Becegato \& Ferreira (2005), utilizaram a gamaespectrometria no entendimento da distribuição de fertilizantes fosfatados, aplicados à cultura da soja, cana-deaçúcar e trigo, no noroeste do Paraná. Segundo estes autores, a baixa concentração de radionuclídeos nas camadas amostradas deve-se ao baixo teor de matéria orgânica o qual não propiciaria a elevação da troca catiônica e a textura arenosa do solo possibilitando, dessa maneira, a lixiviação dos radionuclídeos para camadas mais profundas do solo, ou transporte superficial por processos erosivos.

0 escopo do presente trabalho consistiu no levantamento, processamento e interpretação de dados gamaespectrométricos terrestre em uma plantação de tomate, localizada na bacia hidrográfica do rio São Domingos, município de São José de Ubá, noroeste do estado do Rio de Janeiro, visando avaliar a aplicabilidade do método em área utilizada para 0 cultivo agrícola. Pretendeu-se, mais especificamente, verificar possíveis concentrações/alterações dos radionuclídeos no solo cultivado e analisar suas relações com atributos de fertilização.

\section{OS RADIONUCLÍDEOS NO SOLO}

A radioatividade dos solos está diretamente relacionada ao material originário que 0 gerou, bem como a processos que atuaram na sua formação. 0 levantamento gamaespectrométrico reflete 
a variação geoquímica do $\mathrm{K}$, do $\mathrm{U}$ e do Th nos $30 \mathrm{~cm}$ superiores da superfície da terra. Essa fina camada é sujeita aos efeitos do intemperismo, que conduz à perda de $\mathrm{K}$ em todos os tipos de rochas e, para as rochas félsicas, perdas também, de U e Th. A extensão da perda dependerá de muitos fatores, mas os valores médios estão entre 20-30\% para os três radioelementos segundo Wilford et al. (1997). De acordo com os mesmos autores, durante o intemperismo químico e físico, os radioelementos são liberados da rocha, redistribuídos e incorporados ao regolito/solo (intemperizado in situ ou proveniente de transporte). Em muitos casos, as características dos radioelementos de regolitos podem diferir significativamente da fonte, devido à re-organização textural e geoquímica que ocorre no perfil intemperizado. As rochas intermediárias e básicas mostram pouca mudança dos radioelementos durante 0 intemperismo inicial. No entanto, a pedogênese pode resultar em solos com duas ou três vezes mais $U$ e Th que a rocha mãe. A interpretação do grau de intemperismo e as respostas gama requerem a compreensão das características dos radioelementos na rocha mãe, bem como do material intemperizado. Assim, deve-se ter muita precaução quando essas relações são utilizadas no processo de interpretação de levantamentos gamaespectrométricos, dependendo da natureza do material de origem e da história do intemperismo.

\section{ÁREA DE ESTUDO}

A bacia hidrográfica do rio São Domingos (BHRSD), afluente do rio Muriaé pertencente ao complexo rio Paraíba do Sul, possui uma área aproximada de $280 \mathrm{~km}^{2}$. Cerca de $90 \%$ da bacia de drenagem do rio São Domingos localiza-se no município de São José de Ubá e os outros 10\% no município de ltaperuna. 0 município de São José de Ubá situa-se a $286 \mathrm{~km}$ da cidade do Rio de Janeiro, na porção noroeste do Estado (Fig. 1). São José de Ubá caracteriza-se por pequenas propriedades com agricultura familiar de baixo nível tecnológico de manejo do solo. É 0 terceiro maior produtor de tomate (Lycopersicon esculentum Mil/) do estado do Rio de Janeiro e constitui uma área predominantemente agrícola que vem sofrendo um intenso êxodo rural. Sua economia gira em torno da agropecuária e da atividade hortícola, sendo o cultivo do tomate a principal atividade econômica local.

No contexto geológico, a BHRSD apresenta as seguintes entidades de mapeamento: complexo Juiz de Fora, com rochas de mais de 1,8 bilhão de anos, complexo Paraíba do Sul, constituído por rochas metassedimentares marinhas com idade aproximada de 1,7 bilhão de anos, e sedimentos fluviais do Quaternário (Silva
Filho, 2005). De acordo com estudos recentes realizados por Lumbreras et al. (2006), a BHRSD apresenta a ocorrência de dois domínios pedológicos distintos e fortemente relacionados às duas feições geomorfológicas regionais: as baixadas (várzeas) e os morros e montanhas. Nas regiões de baixadas, foram identificados Gleissolos nas partes mais baixas e Planossolos e Cambissolos desenvolvidos de sedimentos coluvionares e colúvioaluvionares nas posições levemente mais elevadas. As áreas de morros e montanhas apresentam domínio de Argissolos vermeIhos e vermelho-amarelos que gradualmente dão lugar a Cambissolos e a Neossolos litólicos à medida que o relevo fica mais acentuado. Segundo os mesmos autores, os Argissolos vermeIhos e vermelho-amarelos compreendem cerca de $70 \%$ da área da bacia hidrográfica do rio São Domingos. Na região da sub-bacia Barro Branco, desenvolveram-se predominantemente Argissolos vermelhos e vermelho-amarelos localizados em áreas de relevo ondulado a fortemente ondulado e montanhoso. A área de estudo está localizada num Nitossolo vermelho eutrófico, o qual apresenta textura argilosa/muito argilosa e que se desenvolveu em relevo fortemente ondulado (Calderano Filho et al., 2006). A área da pesquisa localiza-se em uma comunidade agrícola denominada Barro Branco (BB).

A sub-bacia BB apresenta elevado índice de antropização e degradação, possui intensa ocupação em pequenas propriedades e um centro rural-urbano módico. Localizada nas coordenadas UTM 7633720 e 190920, zona 24K, a área de estudo perfaz três parcelas com um total aproximado de $25 \times 60 \mathrm{~m}$ (Fig. 2) a qual é monitorada pela Embrapa. Para cada parcela foram utilizados diferentes tipos de plantio. Na primeira (1) utilizou-se o plantio convencional (PC), que consiste no máximo revolvimento do solo através de aração seguido por duas gradagens. Na segunda (2) 0 solo foi preparado com a prática do cultivo mínimo (CM), que tem como objetivo minimizar o uso de máquinas agrícolas, com a finalidade de menor revolvimento e compactação. Nessa prática o solo foi revolvido somente com um arado. Na terceira (3) utilizou-se o plantio direto (PD), que consiste na semeadura direta sem preparo do solo, em que há leve abertura do sulco para a disposiçãa das sementes diretamente sobre a resteva de outra cultura com finalidade de manter 0 solo coberto. Nas parcelas 1 e 20 sistema de rega utilizado foi por aspersão, enquanto que na parcela 3 aplicou-se 0 sistema de gotejamento nos sulcos com aproximadamente 2 a 3 litros/h. 0 tomate é cultivado no período de março a outubro, e nos outros meses cultiva-se milho, arroz e feijão. Entre os insumos agrícolas utilizados na plantação estão: os fertilizantes (mineral misto $0(\mathrm{~N}) 70(\mathrm{P}) 30(\mathrm{~K})$, superfosfato simples e de cova $4(\mathrm{~N}) 14(\mathrm{P}) 8(\mathrm{~K}))$. 


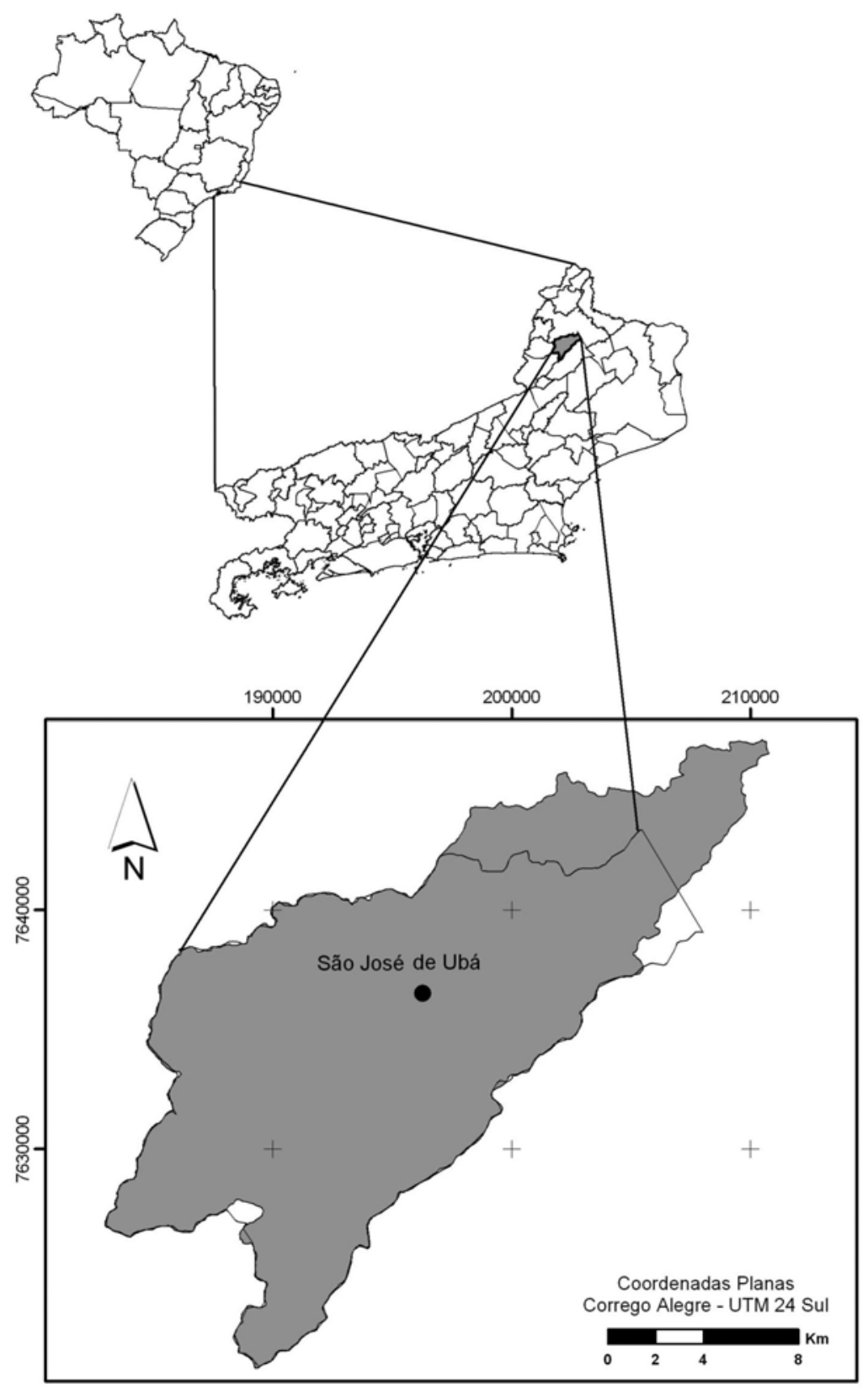

Figura 1 - Mapa de localização do município de São José de Ubá no estado do Rio de Janeiro.

\section{AQUISIÇÃO DE DADOS}

0 projeto inicial deste trabalho consistia no levantamento geofísico da área de estudo, em campo, empregando-se um gamaespectrômetro portátil. Ocorre que durante a execução deste levantamento, problemas técnicos com o equipamento inviabilizaram a aquisição de dados. Por este motivo, optou-se por coletar amostras de solo para posterior medição gamaespectrométrica no laboratório.
Foram coletadas 75 amostras no solo na área de cultivo, buscando obedecer a uma malha regular com espaçamento de $5 \times 5 \mathrm{~m}$. Seis (6) amostras de solo foram coletadas em área não cultivada e uma (1) amostra de rocha em afloramento situado a aproximadamente 100 metros a leste da plantação (Fig. 3). As amostras de solo que correspondem à porção entre 0 e 15 centímetros de profundidade, foram utilizadas para medição da radioatividade, análise física (determinação de textura) e difratometria de raio $X$. 


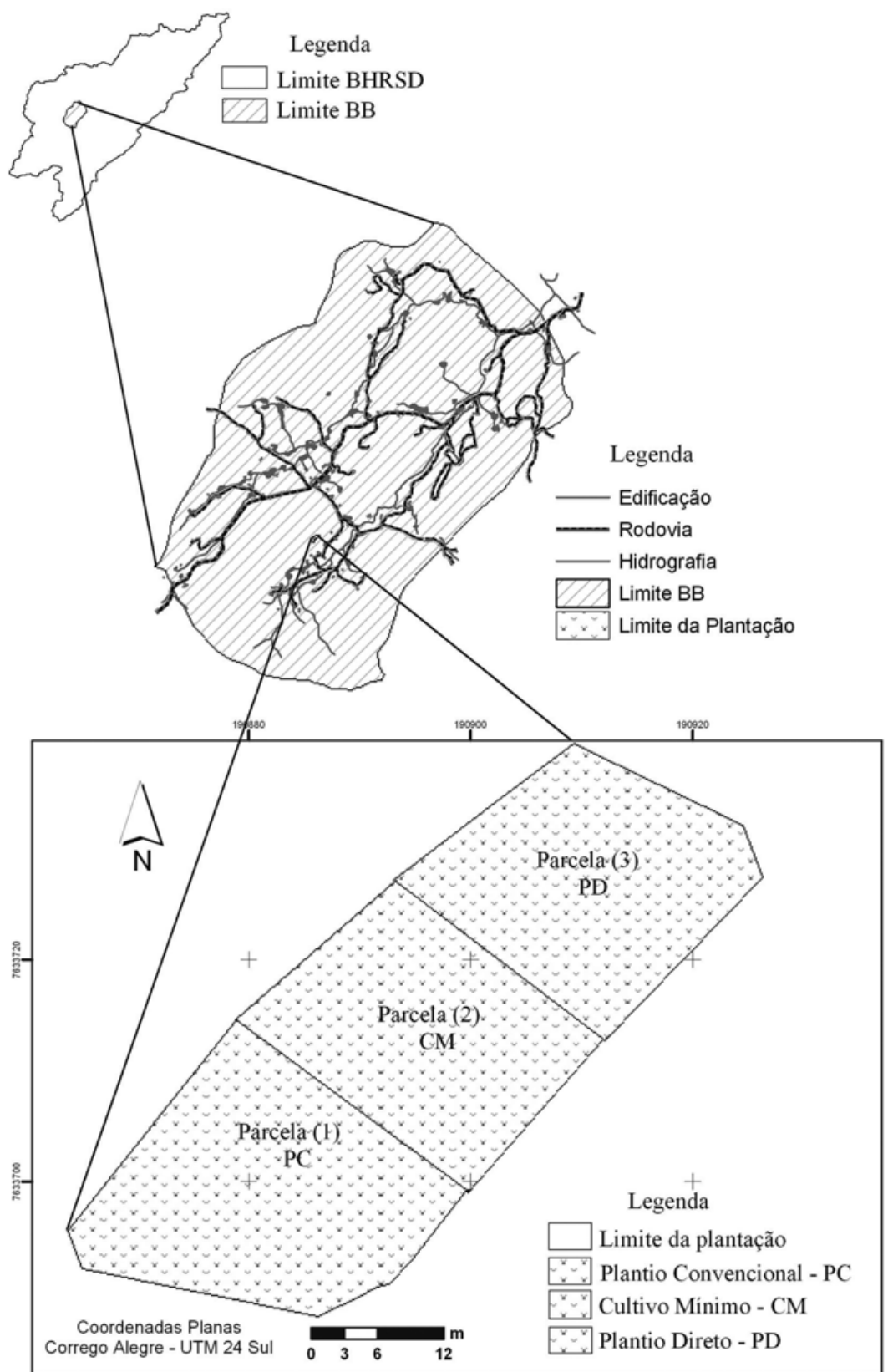

Figura 2 - Mapa de localização da área de cultivo.

0 GRS-500 é um gamaespectrômetro fabricado por Scintrex Limited, Canadá. Ele é constituído por um único módulo, medindo 23,5 × 11,5 × 6,4 cm e cujo peso é de aproximadamente $2,5 \mathrm{~kg}$. Neste módulo está embutido 0 detector, constituído por um cristal de iodeto de sódio ativado por tálio (Nal(TI)), com volume de $124 \mathrm{~cm}^{3}$, acoplado a uma unidade fotomultiplicadora. A alimentação é feita por 4 pilhas alcalinas tamanho "C". A calibração do aparelho pode ser verificada me- diante 0 uso de uma fonte padrão de 133Ba, que acompanha 0 equipamento (Scintrex, 1997).

0 GRS-500 permite medir a radiação gama emitida durante 0 decaimento dos isótopos de $\mathrm{K}, \mathrm{U}$ e Th. As leituras obtidas com este aparelho são expressas em cps (cintilações por segundo). 0 GRS-500 não fornece leituras em \% de K ou ppm de U e Th. Embora seja possível fazer a conversão das leituras de cps para percentagem ou ppm, tem-se observado, em outros trabalhos 


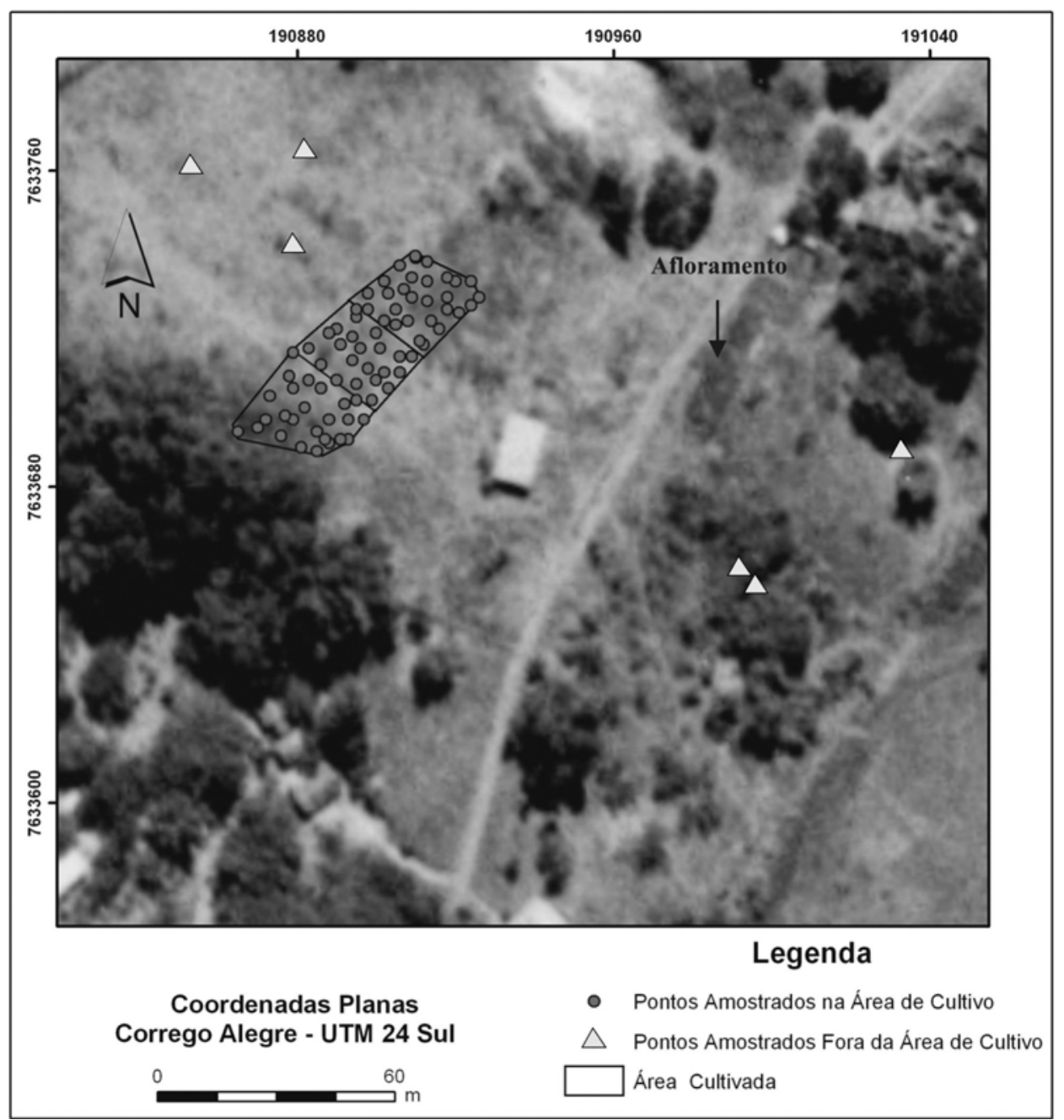

Figura 3 - Mapa de localização dos pontos amostrados na área de estudo.

empregando 0 GRS-500, que a prática comum é expressar os resultados em cps (Machado \& Penha, 1997; Souza \& Ferreira, 2005).

Para o levantamento gamaespectrométrico foram utilizadas cerca de 300 gramas de cada amostra de solo, de rocha e dos fertilizantes superfosfato simples e NPK (4-14-8). 0 procedimento consistiu em colocar cada amostra em contato direto com o GRS500 , durante um período de 3 minutos, período ao final do qual se obteve as leituras de contagem total, $\mathrm{K}, \mathrm{U}$ e Th. Durante 0 processo de medição, cada amostra e o próprio GRS-500 ficaram parcialmente inseridos numa caixa plástica, revestida com placas de chumbo de modo a reduzir a influência da radiação do ambiente na leitura da amostra.

A metodologia utilizada para o processamento dos dados terrestres envolveu levantamento, avaliação dos dados, interpolação e geração de imagens gamaespectrométricas. A interpretação dos dados consistiu de análise visual das imagens radiométricas, análise estatística e correlação com as demais variáveis disponíveis. As leituras com o equipamento GRS-500 são expressas originalmente em contagens por segundo (cps) e durante o processamento das leituras, optou-se por manter esta forma de expressão (Santos, 2007). Isto se justificou pelo fato de que durante a análise de grupos, todas as variáveis envolvidas foram padronizadas, com a conseqüente eliminação das unidades. Durante a padronização, cada valor foi subtraído da média da variável e dividido pelo respectivo desvio padrão, conforme Davis (1986). Os dados foram interpolados por meio de krigagem, após testes preliminares com a triangulação, inverso da distância e mínima curvatura.

0 objetivo da realização da análise de difratometria de raios- 
$X$ foi 0 de definir os argilominerais presentes no solo. 0 ensaio compreendeu três etapas: preparação, análise e identificação/ interpretação do difratograma, conforme descrito por Guimarães (1999).

A análise granulométrica foi realizada através dos métodos padronizados determinados por Malvern Instruments (1997). Para esse processamento, foram utilizadas 81 amostras: 75 da área da plantação e 6 fora da plantação. Para 0 processo de caracterização através do granulômetro a laser, parte das amostras, após a fase de secagem ao ar livre, foram separadas para determinação de umidade, pesadas, alíquotas de aproximadamente $100 \mathrm{~g}$ e destorroadas. Após este processo, foram submetidas ao peneiramento (\#2 mm). 0 material retido nessa peneira foi lavado, seco em estufa e posteriormente submetido ao peneiramento grosso (\#50,8 a 4,76 mm). 0 material passante na peneira com abertura de \#2 $\mathrm{mm}$ foi submetido à peneira de abertura $\# 0,42 \mathrm{~mm}$. 0 retido neste último peneiramento foi lavado, seco em estufa e submetido ao peneiramento fino (\#1,19 mm e $0,59 \mathrm{~mm}$ ) e o passante foi separado e utilizado para caracterização no granulômetro a laser. De um modo geral, o material apresenta uma característica siltosa, o que se deve a pouca eficiência do granulômetro a laser como desagregador de silte, uma vez que converteu pouca matéria em argila.

\section{RESULTADOS}

Na imagem do Th (Fig. 4), observam-se valores altos, médios e baixos nas três parcelas, embora exista uma tendência dos maiores valores concentrarem-se nas bordas norte e noroeste da área, enquanto que os menores concentram-se na borda sudeste. A imagem do K (Fig. 5) apresenta menores valores na porção nordeste, a qual coincide com a área do PD e maiores nas porções sul e sudoeste, que corresponde ao PC. Além disto, observa-se uma região ao noroeste de altos valores no limite entre $0 \mathrm{CM} e$ o PD. Na imagem do U (Fig. 6), observam-se valores médios e baixos distribuídos de forma homogênea nas três parcelas, exceto no caso da amostra 125, situada na área de CM. Essa anomalia pode estar representando uma mancha de solo com excesso de adubo fosfatado. A imagem da CT (Fig. 7) os maiores valores cobrem quase toda a área de cultivo. Na porção sul das parcelas $\mathrm{CM}$ e PD, predominam os menores valores.

A partir das medidas obtidas com 0 gamaespectrômetro, correlacionou-se as contagens encontradas na área de cultivo, com a não cultivada (determinada para branco) e os valores referentes aos radionuclídeos nos fertilizantes medidos (superfosfato simples e NPK). Os dados apresentados estão em cps de
Th, K, U e CT, e também em Bq/Kg, com o objetivo de facilitar comparações com a literatura internacional. Assim, as relações adotadas foram as seguintes: $1 \mathrm{cps}$ equivale a $1 \mathrm{~Bq} / \mathrm{Kg}$ (Tab. 1).

Os resultados apresentados na Tabela 1 indicam que os fertilizantes utilizados na área cultivada apresentam contagens de radionuclídeos maiores que os observados nas parcelas $\mathrm{PC}, \mathrm{CM}$ e PD, além das áreas ao norte (AC) e ao sul (AB) da plantação, nas quais foram coletadas 6 amostras como referência do solo local sem fertilizante. Dos fertilizantes analisados, o superfosfato simples, foi o que apresentou as maiores concentrações de radioelementos. Vários autores atribuem a presença de radionuclídeo, em especial $0 \mathrm{U}$, nos fertilizantes derivados de rochas fosfatadas. De acordo com Rothbaum et al. (1979), durante a preparação do fertilizante superfosfato, o U permanece como sulfato de uranila e sulfato uranoso, ambos solúveis em água. Os teores encontrados na rocha indicam que o material de origem dos solos da área estudada apresenta contagens maiores que os encontrados nos solos. Os solos das parcelas cultivadas e o solo considerado como branco apresentaram características muito próximas de radionuclídeos, sendo possível diferenciá-los com limitações. Os dados observados estariam indicando que os solos estão perdendo os radioelementos do material de origem a partir de processos pedogenéticos. 0 intemperismo existente na área estaria exercendo um papel crítico na concentração dos radioelementos como justificam Dickson \& Scott (1997) e Wilford et al. (1997). Outro indicativo do intemperismo atuante naquele local é a presença do quartzo e da caulinita como os minerais mais freqüentemente encontrados nas amostras, conforme mostram os difratogramas (Figs. 8 e 9).

\section{INTEGRAÇÃO DA GAMAESPECTROMETRIA COM AS DEMAIS VARIÁVEIS DO SOLO}

À medida que se caminha em direção a leste da plantação, observa-se a redução de argila na ordem de 10\% (Fig. 10). Esse solo de característica menos argilosa coincide com a área onde são menos abundantes os elementos U e K.

Além da análise granulométrica, efetuou-se também a determinação do teor de umidade presente nas amostras coletadas. Os valores de umidade foram correlacionados com os de argila + silte, observando-se uma relação diretamente proporcional (Fig. 11).

Trata-se de um resultado esperado, visto que a redução da textura tende a causar um aumento na retenção de umidade. Com 0 intuito de complementar as análises anteriores e melhor diferenciar os três tipos de manejo na área cultivada, efetuou-se uma análise de grupos. A análise de agrupamentos consiste numa 

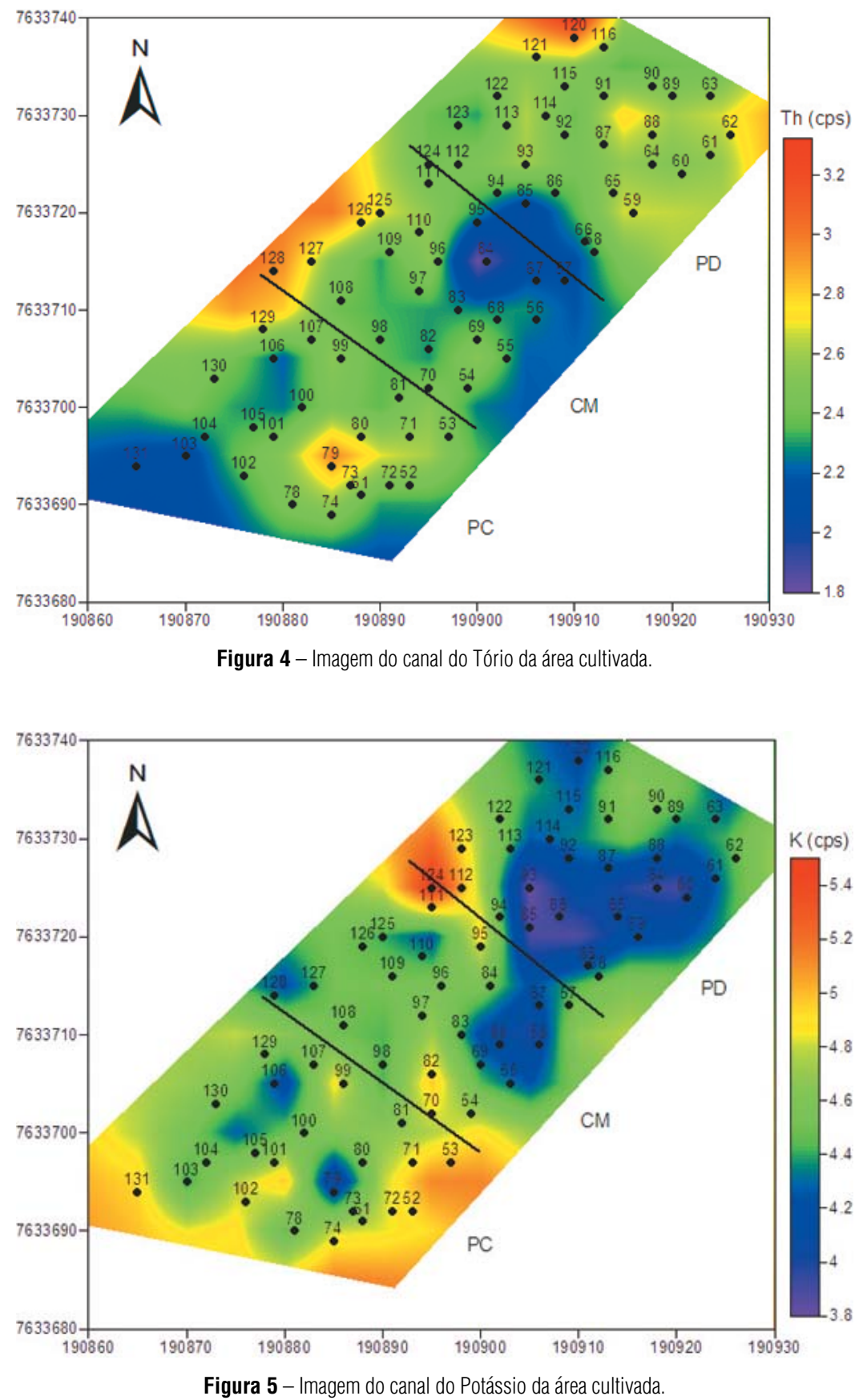

técnica que procura estabelecer grupos dentro de um conjunto maior de objetos (Davis, 1986). A análise foi realizada com os valores padronizados de argila+silte, CT, K, U e Th e interpolados com célula de 2,5 m, cujo número de grupos é definido pelo analista. Efetuaram-se testes usando 2, 3, 4 e 5 grupos e somente com 5 foi possível obter uma divisão da área cultivada em três segmentos, os quais poderiam estar refletindo os diferentes tipos de manejo (Fig. 12).

Na Figura 12, observam-se três grupos principais $(4,1,5)$ e dois grupos de menor importância (2 e 3). A principal variável que pode justificar a existência destes grupos é a textura. Além desta, as variáveis radiométricas também foram empregadas na geração desta imagem, e, portanto também exercem influência. Correlacionando as Figuras 12 e 10, observa-se que 0 grupo 5 


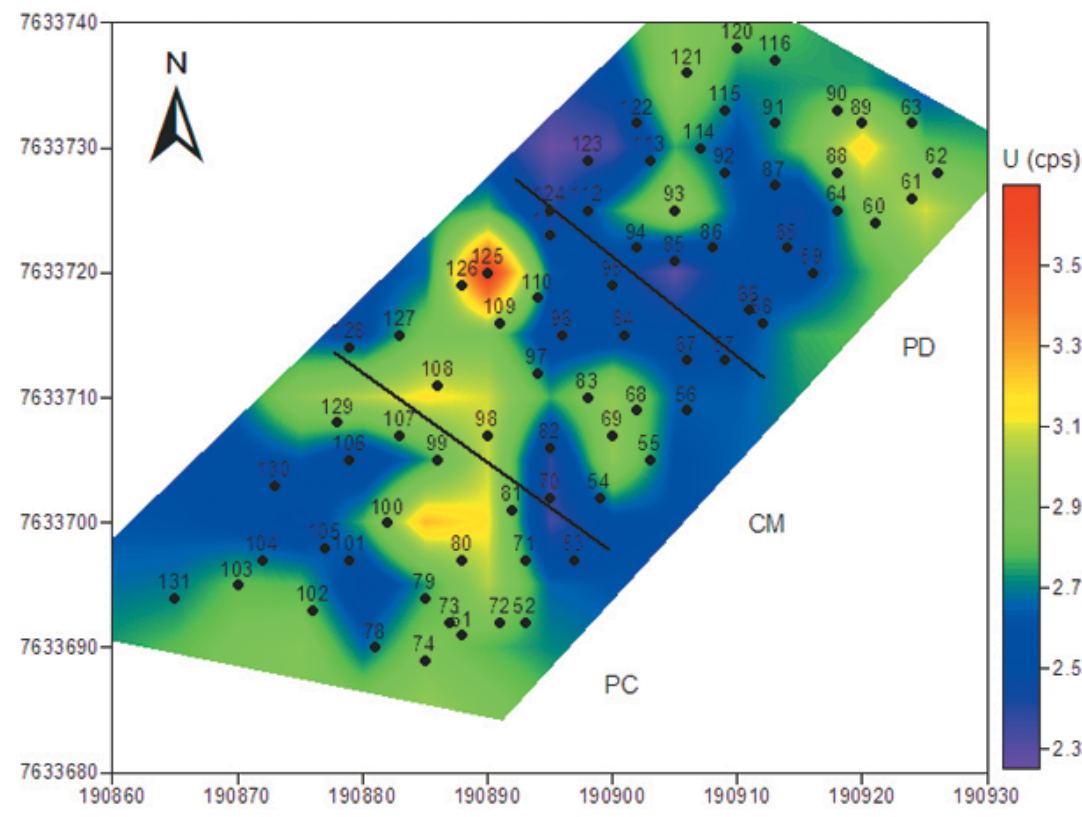

Figura 6 - Imagem do canal do Urânio da área cultivada.

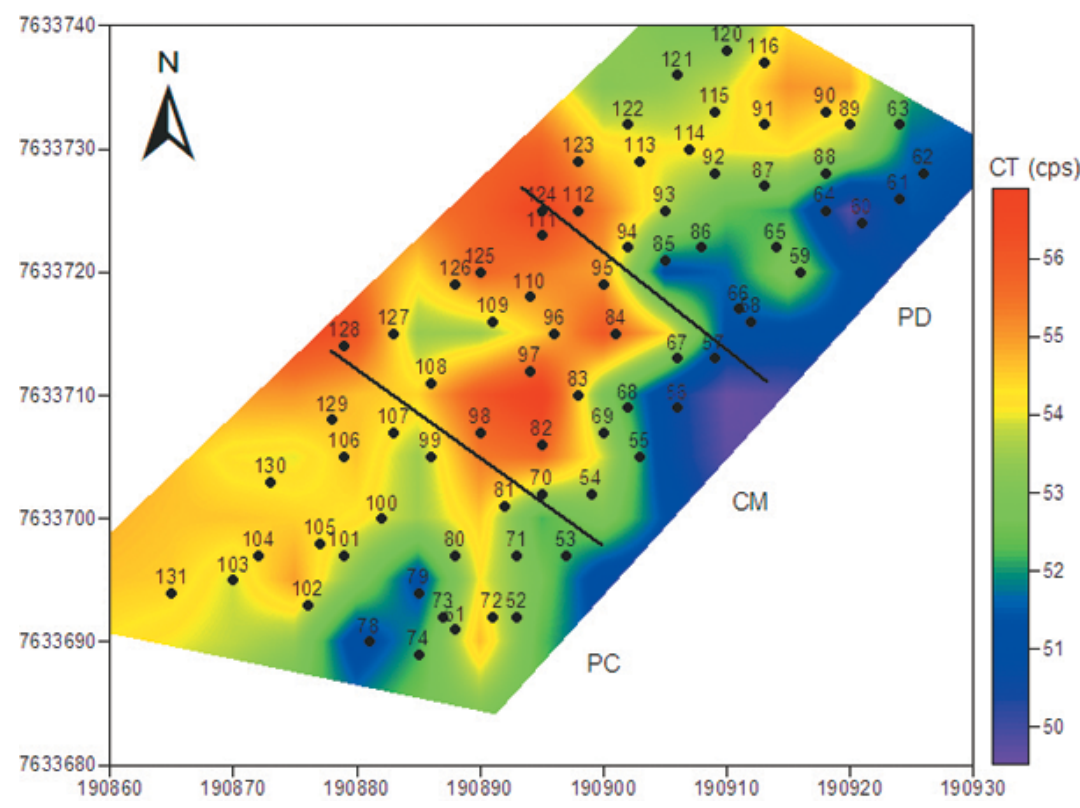

Figura 7 - Imagem do canal Contagem Total da área cultivada.

(vermelho) corresponde à região mais argilosa. De forma semeIhante, o grupo 4 (violeta) refere-se à região menos argilosa e 01 (verde) corresponde a uma condição textural intermediária. A correlação entre as Figuras 12 e 7 demonstra que 0 grupo 3 (azul) representa às áreas mais radioativas, enquanto 0 grupo 2 (amarelo) diz respeito às áreas menos radioativas.
Em princípio, associa-se o grupo 4 (violeta) ao PD, 01 (verde) ao CM e 05 (vermelho) ao PC. Contudo, o mais correto é fazer a associação entre os grupos e o efeito combinado da radiação gama e da textura. Deste modo tem-se o grupo violeta representando uma área menos argilosa e menos radioativa. 0 grupo verde representando condições intermediárias de textura e de radioati- 
Tabela 1 - Médias das contagens de U, Th K e CT para a área cultivada, não cultivada, rocha e fertilizantes utilizados na plantação em estudo. $A C$ (ao norte), $A B$ (ao sul).

\begin{tabular}{|c|c|c|c|c|c|c|c|c|}
\hline Amostra & $\mathrm{U}(\mathrm{cps})$ & $\mathrm{U}(\mathrm{Bg} / \mathrm{Kg})$ & $\mathrm{Th}(\mathrm{cps})$ & $\mathrm{Th}(\mathrm{Bg} / \mathrm{Kg})$ & $\mathrm{K}(\mathrm{cps})$ & $\mathrm{K}(\mathrm{Bq} / \mathrm{Kg})$ & $\mathrm{CT}(\mathrm{cps})$ & $\mathrm{CT}(\mathrm{Bq} / \mathrm{Kg})$ \\
\hline $\mathrm{PC}$ & 2,7 & 2,7 & 2,4 & 2,4 & 4,6 & 4,6 & 53,5 & 53,5 \\
\hline $\mathrm{CM}$ & 2,7 & 2,7 & 2,4 & 2,4 & 4,4 & 4,4 & 54,1 & 54,1 \\
\hline $\mathrm{PD}$ & 2,7 & 2,7 & 2,5 & 2,5 & 4,3 & 4,3 & 53,1 & 53,1 \\
\hline $\mathrm{AC}$ & 2,6 & 2,6 & 2,5 & 2,5 & 5,2 & 5,2 & 57,2 & 57,2 \\
\hline $\mathrm{AB}$ & 2,7 & 2,7 & 2,4 & 2,4 & 4,4 & 4,4 & 53,4 & 53,4 \\
\hline Rocha & 3,2 & 3,2 & 3,2 & 3,2 & 4,9 & 4,9 & 64 & 64 \\
\hline $\begin{array}{c}\text { Fertilizante } \\
\text { super simples }\end{array}$ & 3,8 & 3,8 & 3,2 & 3,2 & 6,6 & 6,6 & 76,4 & 76,4 \\
\hline Fertilizante NPK & 3 & 3 & 3 & 3 & 5,9 & 5,9 & 61,8 & 61,8 \\
\hline
\end{tabular}

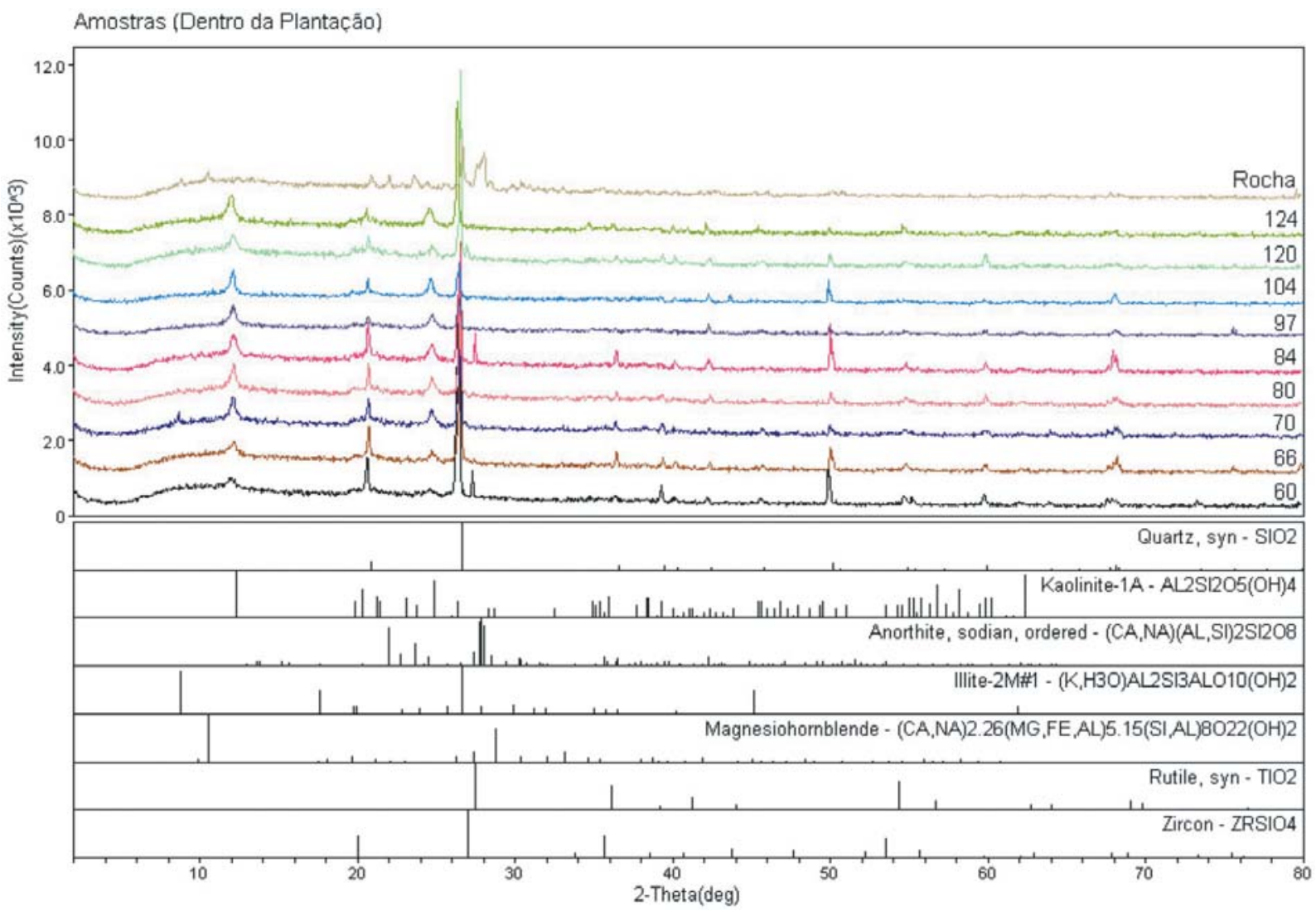

Figura 8 - Difratometria de Raios-X para solos dentro da área de cultivo.

vidade. Os grupos vermelho e azul correspondendo a condições mais argilosas e mais radioativas. Finalmente, 0 grupo amarelo corresponde a condições texturais intermediárias e radioativas baixas. 0 fato de os grupos azul e vermelho mostrarem condições semelhantes em relação às imagens de CT e de textura não implica que sejam idênticos. As leituras das outras variáveis de forma independente também foram empregadas na elaboração da imagem dos grupos. A imagem do Th, por exemplo, mostra altos valores na borda noroeste da área de cultivo, e esses valores podem estar levando ao surgimento do grupo azul. 


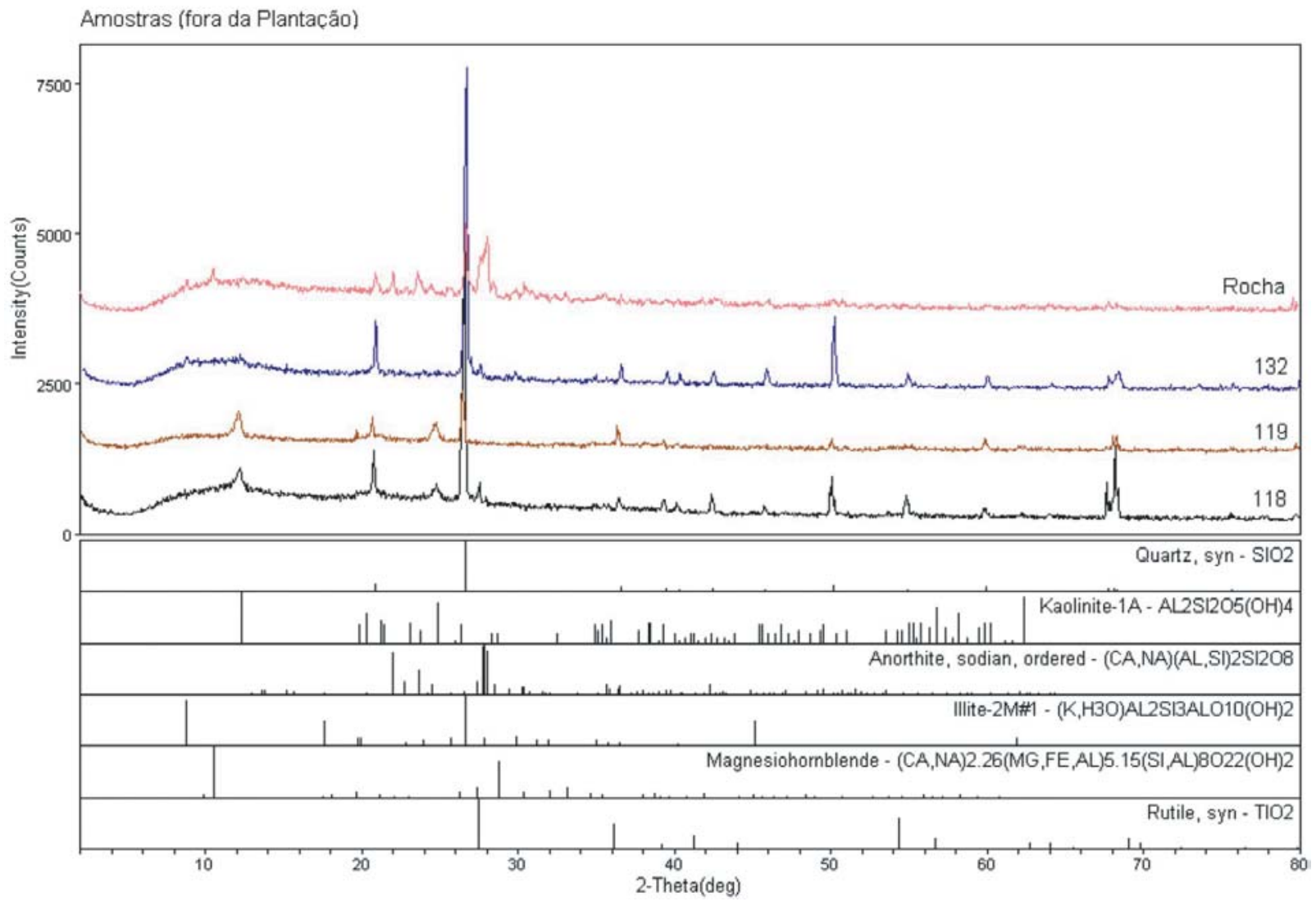

Figura 9 - Difratometria de Raios-X para solos fora da área de cultivo.

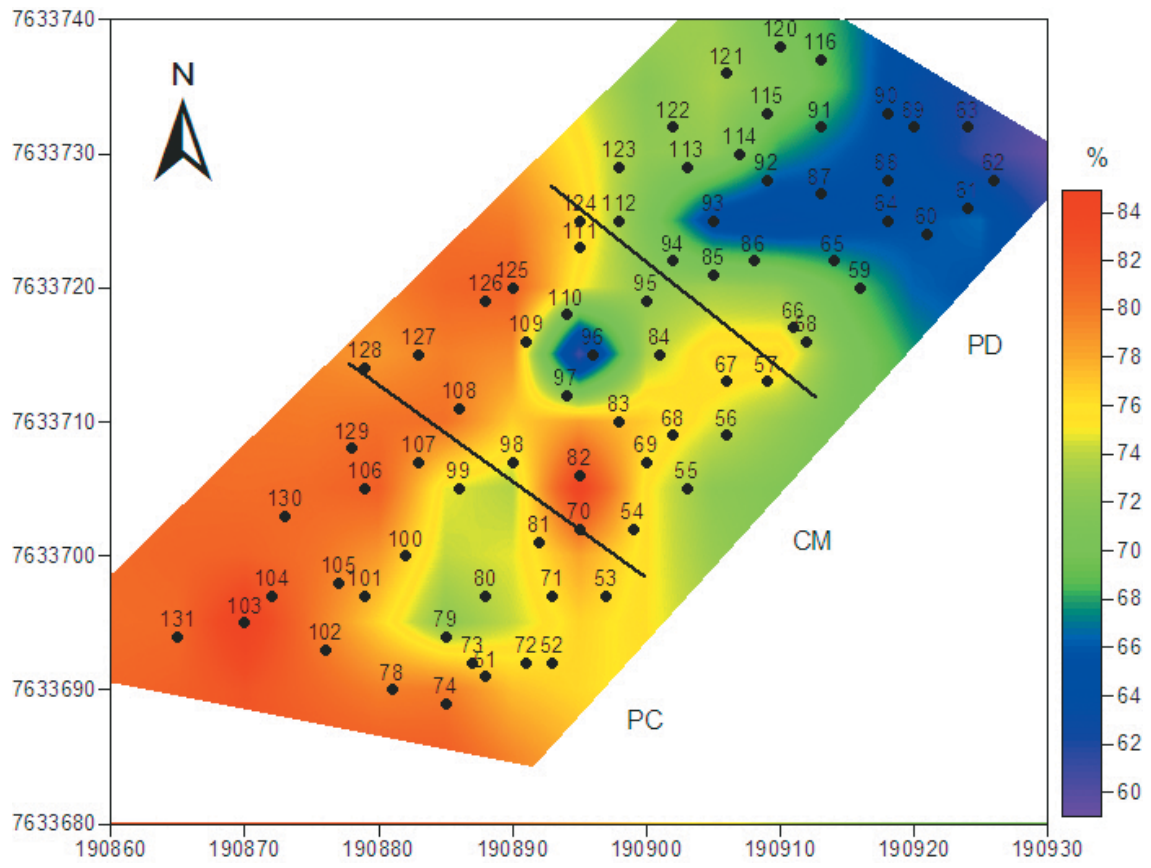

Figura 10 - Distribuição espacial dos teores de argila + silte na área cultivada. 


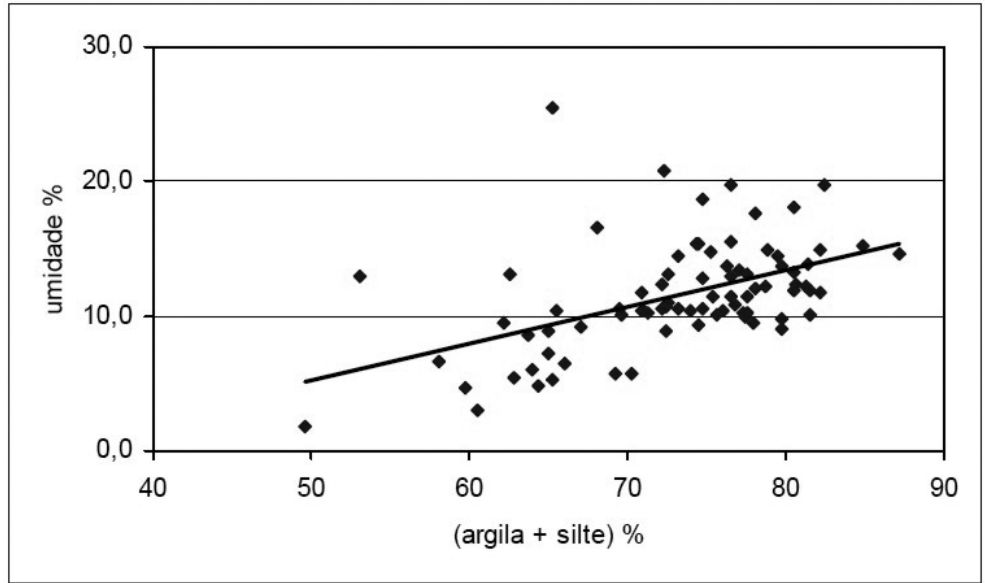

Figura 11 - Teores de umidade versus argila + silte.

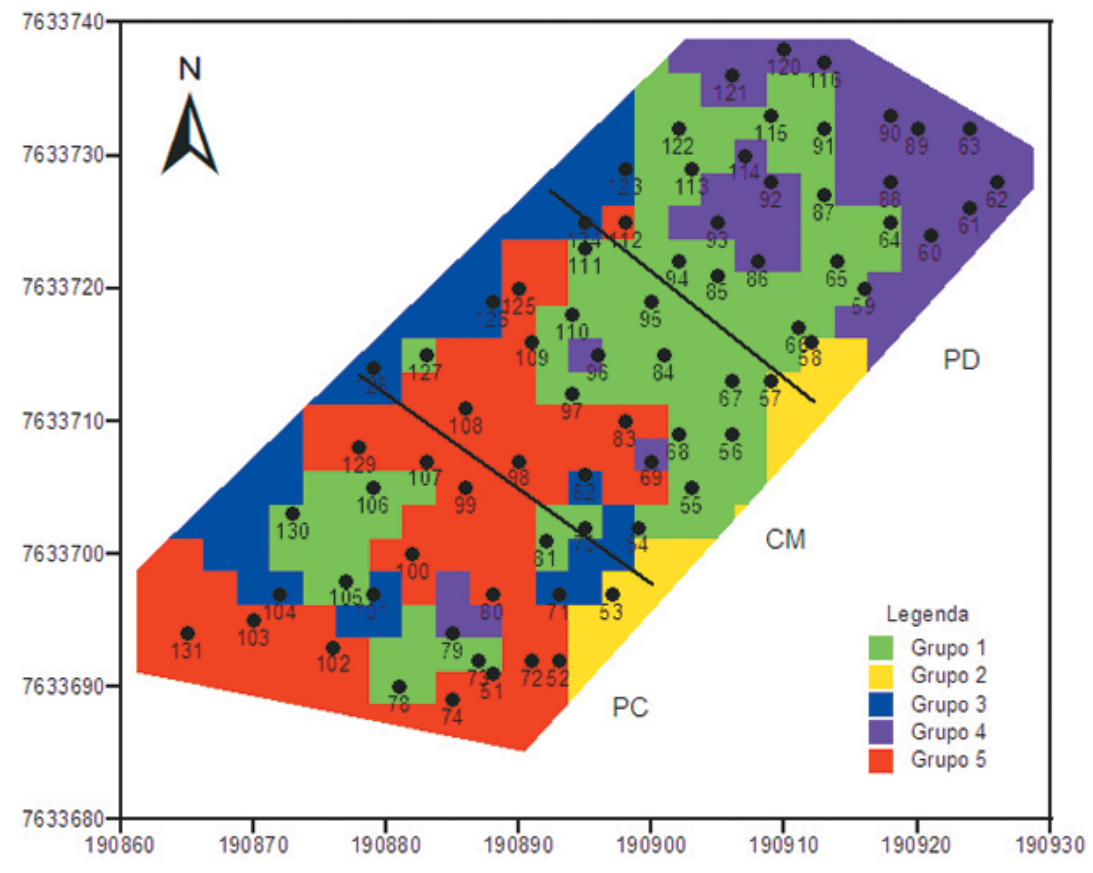

Figura 12 - Imagem da análise de grupos da área cultivada.

\section{CONCLUSÕES}

A integração com as diferentes variáveis do solo permitiu a interpretação do comportamento dos radionuclídeos U, Th e K na área estudada. A área do PD apresenta característica menos argilosa que os outros dois manejos, com uma redução de argila na ordem de $10 \%$. Esse solo de característica menos argilosa coincide com a área onde os elementos U e K são menos abundantes, além de menos úmida. Isso seria esperado, visto que a redução da fração argila tende a causar uma redução na retenção de umi- dade. Não foi possível observar grande diferenciação com base na radiometria para os três diferentes manejos, o que pode estar relacionado com a falta de conhecimento do histórico da área. Contudo, é de esperar-se que ao longo do tempo, mantendo-se as mesmas características de plantio, possa observar-se melhor a diferenciação radiométrica entre as parcelas. Um dos aspectos mais importante neste trabalho envolveu a comparação entre os dados radiométricos coletados em rocha e no solo da plantação. Tal comparação indica que o $\mathrm{U}$ e 0 Th estão sendo lixiviados na ordem de $20 \%$. Em contrapartida, $0 \mathrm{~K}$ apresenta taxas de lixiviação 
menores, cerca de 10\%. Interpretou-se esta menor taxa de queda devido ao emprego dos fertilizantes na plantação. Os números aqui apresentados confirmam a interpretação da existência de zona de lixiviação realizada nos dados aéreos. Essa lixiviação pode ser uma das possíveis causas para a necessidade da grande quantidade de aplicação de fertilizantes na região. 0 estudo apresentado mostra que é possível a utilização da gamaespectrometria para fins de identificação e monitoramento de processos pedogenéticos e de agricultura.

\section{AGRADECIMENTOS}

Os autores agradecem a Universidade de Brasília (IG/LGA) e a CAPES, que possibilitaram os meios acadêmicos e econômicos; a CPRM, DRM e Embrapa (PRODETAB), pelos dados cedidos.

\section{REFERÊNCIAS}

ARANHA PRA, AUGUSTIN CHRR \& SOBREIRA FG. 2002. The use of GPR for characterizing underground weathered profiles in the sub-humid tropics. Journal of Applied Geophysics, 49: 195-210.

BACCHI O0S, REICHARDT K, OLIVEIRA JCM \& NIELSEN DR. 1998. Gamma-ray beam attenuation as an auxiliary technique for the evaluation of the soil water retention curve. Scientia Agricola, Piracicaba, 55(3): 498-502.

BECEGATO VA \& FERREIRA FJF. 2005. Gamaespectrometria, resistividade elétrica e susceptibilidade magnética de solos agrícolas no noroeste do estado do Paraná. Rev. Bras. Geof., 23(4): 371-405.

CALDERANO FILHO B, CHAGAS CS, PRADO RB, PEREZ DV, GONÇALVES AO \& SOUZA JS de. 2006. Levantamento semidetalhado doS solos da microbacia do Barro Branco, no município de São José de Ubá, região noroeste do estado do Rio de Janeiro. Rio de Janeiro, Boletim de Pesquisa, Embrapa Solos, (no prelo).

DAVIS JC. 1986. Statistics and data analysis in geology. $2^{\text {nd }}$ ed., New York, John Wiley \& Sons, 646 pp.

DICKSON BL \& SCOTT KM. 1997. Interpretation of aerial gamma-ray surveys- adding the geochemical factors. AGSO Journal of Australian Geology \& Geophysics, 17: 187-200.

DICKSON BL, FRASER SJ \& KINSEY-HENDERSON A. 1996. Interpreting aerial gamma-ray surveys utilising geomorphological and weathering models. Elsevier, Journal of Geochemical Exploration, 57: 75-88.

ELIAS EA. 2004. Equations Gamma-Ray attenuation systems with beam directed vertically, along gravitational field. Revista de Agricultura, 79: 169-176.

GUIMARÃES EM. 1999. Difratometria de raio-X. In: XXVII Congresso Brasileiro de Ciências do Solo, Brasília, 49 p.
LUMBRERAS JF, NAIME UJ, MOTTA PEF, PALMIERI F, CARVALHO FILHO A de, BARUQUI AM, CALDERANO SB, FIDALGO ECC, MOREIRA DM \& ABREU MB de. 2006. Solos da bacia hidrográfica do Rio São Domingos, municípios de São José de Ubá e Itaperuna - RJ. In: Workshop de integração de informações obtidas no âmbito do projeto Prodetab Aqǘferos, Rio de Janeiro: Embrapa Solos. CD-ROM.

MACHADO SAM \& PENHA UC. 1997. Estruturação da seqüência vulcano-sedimentar Rio Mata Cavalo (Morro do Pilar, MG, Brasil) baseada na análise qualitativa de dados geofísicos. Rev. Bras. Geof., 15(2): 145-152.

MALVERN INSTRUMENTS. 1997. Sample Suspension Unit Manual. England. $20 \mathrm{p}$.

METTERNICHT GI \& ZINCK JA. 2003. Remote sensing of soil salinity: potentials and constraints. Elsevier, Remote Sensing of Environment, 85: 1-20.

NASCIMENTO CTC do, PIRES ACB \& MORAES RAV de. 2004. Reconhecimento de solos por meio de resistividade elétrica e radiação gama. Rev. Bras. Geoc., 34(3): 383-392.

POZDNYAKOVA L, POZDNYAKOVA A \& ZHANG R. 2001. Application of geophysical methods to evaluate hydrology and soil properties in urban areas. Elsevier, Urban Water, 3: 205-216.

REBELO AMA de. 2000. Processos supergênicos na distribuição de radônio em paisagens tropicais úmidas. Curitiba. Tese de Doutorado, Universidade Federal do Paraná, 209 p.

ROTHBAUM HP, McGAVESTON DA, WALL T, JOHNSTON AE \& MATTINGLY GEG. 1979. Uranium accumulation in soils from long-continued applications of superphosphate. Journal of Soil Science, 30: 47-153.

SANTOS ACL. 2007. Gamaespectrometria aplicada ao estudo de áreas agrícolas. Dissertação de Mestrado, Universidade de Brasília, 212 p.

SCINTREX. 1997. GRS-500 Operations Manual Version 2.0. Concord, Ontario, Canada. Scintrex Limited. $48 \mathrm{p}$.

SILVA FILHO RS. 2005. Metodologias de investigação da potencialidade de aqǘferos fraturados na bacia do rio São Domingos - RJ. Monografia, Faculdade de Geologia, Universidade do Estado do Rio de Janeiro, 62 p.

SOUZA JL. 1998. Anomalias aerogamaespectrométricas (K, U e Th) da Quadrícula de Araras (SP) e suas relações com processos pedogenéticos e fertilizantes fosfatados. Dissertação de Mestrado, Universidade Federal do Paraná, $218 p$.

SOUZA JL \& FERREIRA FJF. 2005. Anomalias aerogamaespectrométricas (K, eU e eTh) da Quadrícula de Araras (SP) e suas relações com processos pedogenéticos e fertilizantes fosfatados. Rev. Bras. Geof., 23(3): 251-274.

TABBAGH A, DABAS M, HESSE A \& PANISSOD P. 2000. Soil resistivity: a non-invasive tool to map soil. Elsevier, Geoderma, 97: 393-404. 
THIESSEN KM, THORNE MC, MAUL PR, PRÖHL G \& WHEATER HS 1999. Modelling radionuclide distribution and transport in the environment. Elsevier, Environmental Pollution, 100: 151-177.

VASCONCELLOS RM, METELO MJ, MOTTA AC \& GOMES RD. 1994. Geofísica em levantamentos geológicos no Brasil. Rio de Janeiro, CPRM, 172 pp.

VAZ CMP, NAIME JM \& MACEDO A. 1999. Soil particle size fractions determined by gamma-ray attenuation. Soil Science, Baltimore, 6: 403-410.
WILFORD JR, BIERWIRTH PN \& CRAIG MA. 1997. Application of gamma-ray spectrometry in soil/regolith mapping and geomorphology. AGSO Journal of Australian Geology \& Geophysics, 17: 201-216.

ZALIDIS G, STAMATIADIS S, TAKAVAKOGLOU V, ESKRIDGE $K$ \& MISOPOLINOS N. 2002. Impacts of agricultural practices on soil and water quality in the Mediterranean region and proposed assessment methodology. Elsevier, Agriculture, Ecosystems \& Environment, 88: $137-146$

\section{NOTAS SOBRE OS AUTORES}

Andréa Cristina Lima dos Santos possui graduação em Geografia pela Universidade do Estado do Rio de Janeiro (2001) e mestrado em Geologia pela Universidade de Brasília (2007). Atualmente é doutoranda em Geologia pela Universidade de Brasília. Tem atuado principalmente com a utilização de métodos radiométricos e eletromagnéticos.

Paulo de Tarso Luiz Menezes possui graduação em Geologia pela Universidade do Estado do Rio de Janeiro (1986), mestrado em Geofísica pela Universidade Federal do Pará (1990) e doutorado em Geofísica pelo Observatório Nacional (1996). Atualmente é professor adjunto da Universidade do Estado do Rio de Janeiro e geofísico - Petróleo Brasileiro S/A. Tem experiência na área de Geociências, com ênfase em Geofísica Aplicada, atuando principalmente nos seguintes temas: exploração de petróleo, prospecção mineral, magnetometria, gravimetria e magnetotelúrico.

Carlos Tadeu Carvalho do Nascimento possui graduação em Geologia pela UnB (1993), mestrado em Tecnologia Ambiental e Recursos Hídricos pela UnB (1998) e doutorado em Geologia pela UnB (2003). Atualmente é Pesquisador Associado da Universidade de Brasília e geólogo da Eletronorte - Centrais Elétricas do Norte do Brasil S.A. Tem atuado principalmente com a utilização de métodos elétricos, eletromagnéticos e radiométricos aplicados a estudos ambientais. 